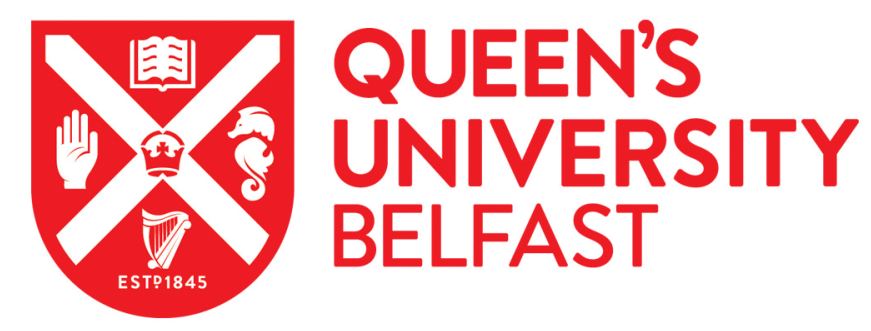

\title{
Highly Stretchable Conductors Based on Expanded Graphite Macroconfined in Tubular Rubber
}

Luo, W., Wu, T., Chen, B., Liang, M., \& Zou, H. (2017). Highly Stretchable Conductors Based on Expanded Graphite Macroconfined in Tubular Rubber. ACS Applied Materials and Interfaces, 43239-43249.

https://doi.org/10.1021/acsami.7b08866

Published in:

ACS Applied Materials and Interfaces

Document Version:

Peer reviewed version

Queen's University Belfast - Research Portal:

Link to publication record in Queen's University Belfast Research Portal

Publisher rights

(c) 2017 American Chemical Society.

This work is made available online in accordance with the publisher's policies. Please refer to any applicable terms of use of the publisher.

\section{General rights}

Copyright for the publications made accessible via the Queen's University Belfast Research Portal is retained by the author(s) and / or other copyright owners and it is a condition of accessing these publications that users recognise and abide by the legal requirements associated with these rights.

Take down policy

The Research Portal is Queen's institutional repository that provides access to Queen's research output. Every effort has been made to ensure that content in the Research Portal does not infringe any person's rights, or applicable UK laws. If you discover content in the Research Portal that you believe breaches copyright or violates any law, please contact openaccess@qub.ac.uk. 


\title{
Highly stretchable conductors based on expanded
}

\section{graphite macro-confined in tubular rubber}

Wei Luo $^{\dagger \ddagger}$, Tongfei Wu ${ }^{\ddagger}$, Biqiong Chen ${ }^{* \ddagger \S}$, Mei Liang ${ }^{\dagger}$, Huawei Zou* ${ }^{* \dagger}$

$\uparrow$ State Key Laboratory of Polymer Materials Engineering, Polymer Research Institute of Sichuan University, Chengdu 610065, China

†Department of Materials Science and Engineering, University of Sheffield, Mappin Street, Sheffield, S1 3JD, UK.

§School of Mechanical and Aerospace Engineering, Queen's University Belfast, Stranmillis Road, Belfast BT9 5AH, UK.

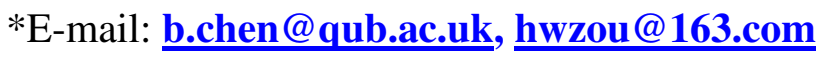

\section{KEYWORDS:}

stretchable conductor, strain sensor, confined packing, expanded graphite

\begin{abstract}
Highly stretchable and durable conductors are significant to the development of wearable devices, robots, human-machine interfaces and other artificial intelligence products. Although many respectable methods have been reported, it is still a challenge to fabricate stretchable conductors with a large elastic limit, high conductivity and excellent reliability in rapid, effective and economic ways. Herein, a facile method is offered to fabricate highperformance stretchable tubular conductors (TCs) based on a macro-confined structure of expanded graphite (EG) in rubber tubing by simply physical packing. The maximum original
\end{abstract}


electrical conductivity of TC reached a high value of $160.6 \mathrm{~S} / \mathrm{cm}$. Meanwhile, TCs showed more insensitive response of conductivity to increasing tensile strain compared to tubular conductors encapsulated with liquid metal or ionic liquid. The conductivity and effective stretchability of TCs can be adjusted by varying the packing density of EG. A low gauge factor below 3 was reached even under $400 \%$ stretching for TC with a packing density of $1.233 \mathrm{~g} / \mathrm{cm}^{3}$. The excellent resilience and good stability of conductivity of TC during dynamic stretching-releasing cycles are attributed to stable and rapid reconstruction of the percolation network of EG particles. The combination of high conductivity, tunable stretchability and good reliability renders TC with potential applications such as highly stretchable interconnects or strain sensors in human motion detection.

\section{INTRODUCTION}

The past decade has witnessed a rapid development of stretchable electronic devices. Such devices with integrated high performance and elastic mechanical responses are promising in the next-generation applications such as stretchable transistors, ${ }^{1-4}$ stretchable light-emitting diodes, ${ }^{5-7}$ smart stretchable sensors, ${ }^{8-10}$ stretchable energy harvesters, ${ }^{11-14}$ and stretchable energy-storage devices ${ }^{15-19}$. As one of the most important components for stretchable electronics, stretchable conductors (SC) can transport electrical signals effectively between electroactive components even under various and harsh mechanical deformations, which make them prospective as electrodes, interconnections or resistors in stretchable electronic devices.

Conventionally, the conductive mechanisms of stretchable conductors are classified into two types: ionic conduction and electrical conduction. A representative case of ionconductive stretchable conductor is the conductive hydrogels, which are highly stretchable, 
transparent and easily deformable materials that exhibit ionic conduction. ${ }^{20,21}$ However, problems such as the low conductivity, ${ }^{22}$ electrochemical reactions,${ }^{23}$ water electrolysis under voltage ${ }^{24}$ evaporation of water during operation and poor mechanical properties ${ }^{25}$ limit the application of a conductive hydrogel as an electronic conductor. For electron-conductive stretchable conductors, the key point that should be considered is how to maintain the effectiveness and reliability of percolation networks even when the structure was under a variety of harsh mechanical deformations. In order to achieve this, various conductive materials including conventional metals (e.g., $\mathrm{Cu}, \mathrm{Ag}, \mathrm{Au})^{26-27}$, liquid metals (e.g., eutectic GaIn (EGaIn), Galinstan) ${ }^{28-29}$, carbon materials (e.g., graphite, carbon fiber, carbon black $)^{4,8-}$ 9,30, nanoscale materials (e.g., nanowires, nanoparticles) $)^{1,16,18,31}$, conductive polymers (e.g., polyaniline, polypyrrole, poly(3,4-ethylenedioxythiophene) $)^{32-33}$ and their hybrids were used as conductive components to combine with various stretchable elastomer substrates.

Although numerous fabrication techniques and methods have been reported, most approaches of integration between conductive materials and elastic substrates can be classified as two main types: conductive networks embedded in a soft matrix and conductive films attached on a soft substrate. In the former cases, researchers have put much attention to conductive elastomer composites. Many methods including traditional blending ${ }^{34-35}$, latex coating then compressing ${ }^{36}$ and casting a polymer into pre-made conductive $3 \mathrm{D}$ networks ${ }^{37}$ were used to secure effective and stretchable conductive percolation paths. However, the contradiction between high conductivity and high stretchability has become the biggest obstacle for traditional conductive elastomer composites. Composites prepared by in-situ formation of 3D conducting networks provided much better conductivity than the traditional blends, but the $3 \mathrm{D}$ conductive network imbedded were usually rigid, and the mismatch between the network and soft matrix caused limited stretchability. ${ }^{38,39}$ Besides, such methods involve tedious steps and high costs, which may not be suitable for scale-up production. 
In recent years, more and more researchers have paid attention to the integration of a conductive thin film with an elastomeric substrate to fabricate stretchable conductors. By designing the structure of the conductive layer as wavy ${ }^{33}$, buckled ${ }^{40}$, wrinkled $^{41}$, serpentine ${ }^{42}$ or other configurations ${ }^{43-45}$, they managed to take advantage of the electrical performance of the nanoscale fillers and obtain good stretchability. However, most of the approaches used to make stretchable electronic devices are complicated, costly, low-yielding, and difficult to control $^{33,41,44}$. Moreover, when suffering large and quick stretching and releasing, big mismatches in the mechanical properties within these conductors caused severe interface delamination between the rigid conductive film and the soft elastomer substrate, which further deteriorated the reliability of the devices ${ }^{46,47}$.

Encapsulating conductive fluids such as liquid metals or ionic liquids within an elastomer gives another way to fabricate stretchable electronic devices in which the conductive material can support deformation. For example, Park et al. ${ }^{48}$ reported a 3D polydimethylsiloxane (PDMS) nano-networks filled with EGaIn, which showed a very high and stable conductivity of $24,100 \mathrm{~S} \mathrm{~cm}^{-1}$ even under $200 \%$ tensile strain. Choi et al. ${ }^{49}$ fabricated a stretchable and transparent strain sensor with high performance by encapsulating ethylene glycol/sodium chloride ionic liquid into a wavy-shaped PDMS channel. Muth ${ }^{9}$ embedded conductive carbon grease into PDMS by an embedded 3D printing method to fabricate highly stretchable strain sensors with more than $400 \%$ stretchability for use as soft functional devices for wearable electronics, human/machine interfaces, and soft robotics. However, to our best knowledge, no reports are available to investigate a stretchable conductor encapsulated with solid conductive particles.

Herein, a macro-confined packing method was developed to readily fabricate tubular conductors (TC) with high conductivity, stretchability and reliability. Expanded graphite (EG), a porous combination of multi-layered graphene with high electrical conductivity and 
low cost was chosen as the packed conductive filler. A highly elastic and strong natural rubber (NR) tubing was selected to provide excellent elasticity and mechanical strength. When the tubing was stretched, the confined EG particles were expected to orientate and slide, yet a robust and stable percolation network could still be maintained when a high amount of EG was packed in the tubing. Meanwhile, the conductivity, sensibility and effective working range of TCs can be tuned by varying the packing density of EG. The combination of high conductivity, stretchablity and good reliability ensures TC potential for serving not only as stretchable electrodes, interconnections and resistors, but as strain sensors to detect the human joint and muscle motions which was demonstrated in this work.

\section{EXPERIMENTAL SECTION}

\section{Materials}

The low temperature expandable graphite (LTEG) with an average particle size of $900 \mu \mathrm{m}$ and initial expanded temperature of $150{ }^{\circ} \mathrm{C}$ was provided by Shijiazhuang ADT trading Co., Ltd (China). The expanded graphite was obtained by expanding $1 \mathrm{~g}$ LTEG in a microwave oven $(800 \mathrm{~W})$ for $30 \mathrm{~s}$. A medical grade natural rubber tubing (Product No. 6707) with an inner diameter of $1.6 \mathrm{~mm}$ and an outer diameter of $3.6 \mathrm{~mm}$ was provided by PAR Group Ltd. Unplated copper wire with a diameter of $2 \mathrm{~mm}$ was purchased from MetalClays4You. A commercial cyanoacrylate glue (AD125) was provided by 3M Company.

\section{Preparation of stretchable tubular conductors (TCs)}

The TCs were fabricated by simply packing EG into a latex rubber tubing. Before filling, the latex rubber tubing was cut to $90 \mathrm{~mm}$ length. Then a copper wire with diameter of $2 \mathrm{~mm}$ was roughened by sandpaper and applied with the commercial glue. The copper wire was inserted into the tubing with an embedded length of $20 \mathrm{~mm}$. After curing $24 \mathrm{~h}$ in ambient condition, 
the half-sealed tubing was ready for filling. Weighed conductive EG powders were packed into the tubing by a funnel and a wooden stick, and then the filling side was also sealed with copper wire and glue. Finally, the packed and sealed tubing was manually stretched to nearly $400 \%$ and released for ten times to promote the uniform dispersion of conductive fillers in the tubing.

\section{Characterization}

Optical microscopy was conducted on a Swift M10T-BTW1-MP benchtop microscope. Scanning electron microscope (SEM) was performed on a microscope (FEI Inspect F) with an acceleration voltage of $5 \mathrm{kV}$. Micro CT scanning was performed on a Skyscan 1172 Micro CT scanning machine with a source voltage of $51 \mathrm{kV}$ and a source current of $149 \mu \mathrm{A}$. The instrument settings provided a resolution of $3.83 \mu \mathrm{m}$ on the samples with a diameter of $2 \sim 3$ $\mathrm{mm}$ and a scan height of $3.6 \mathrm{~mm}$. Samples were fixed on a Perspex sheet with a specific stretching ratio $(0 \%, 250 \%$ and $400 \%)$. In order to reduce noise, the distance between the sheet and tubing sample was kept at $3 \mathrm{~mm}$. Fifty 2D slices for every sample from the results of scanning were analyzed by graphic software to obtain the average area percentage of EG.

The relationships between resistance and strain under stretching and bending were measured by a programed moving platform, which consists of a control motherboard and a stepping motor. The motherboard was connected with a computer. Before testing, the tubular conductor was clamp-mounted on the platform with an initial gap of $10 \mathrm{~mm}$. For the bending test, a poly(ethylene terephthalate) film was cut to fit the gap and put under the sample to maintain vertically deformation of the sample during testing. The resistance-strain curves were acquired by using a four-point probe method (Agilent 34410A multimeter) with an interval sampling time of $0.4 \mathrm{~s}$. The four electrical probes directly contacted the $\mathrm{Cu}$ wire without coating a conductive paste. The moving speed was set as $60 \mathrm{~mm} / \mathrm{min}$. For the 
twisting test, the sample was clamped at a distance of $40 \mathrm{~mm}$, the four-probe resistance values were recorded at each $180^{\circ}$ rotation of the sample. The I-V curves of TC under various stretching $(0-400 \%)$ were measured in the voltage range from $0 \mathrm{~V}$ to $+3 \mathrm{~V}$ by connecting the sample with a programmable voltage source (Keithley 230) and the multimeter. The LED was connected with the stretchable tubular conductor directly and tested under a working voltage of $3 \mathrm{~V}$.

Quasi-static and cyclic tensile tests were conducted on a universal mechanical testing machine (Hounsfield, UK) with a speed of $50-500 \mathrm{~mm} / \mathrm{min}$ and a $1 \mathrm{kN}$ load cell at room temperature. At least 5 samples were tested.

To assemble the stretchable tubular conductor as a strain sensor, the sample was fixed on a finger or arm. Before testing, the whole circuit was checked carefully to make sure that all joints were safely connected and no damage or leak of the TCs was present. The tests of human motion detecting were conducted in real-time by a two-point measurement with the multimeter under a low input voltage $(1 \mathrm{~V})$.

\section{RESULTS AND DISCUSSION}

Expanded graphite or "graphite worm" $" 50$ is the product of graphite intercalation compound after heat treatment. Because of the rapid expansion and exfoliation of graphite platelets during the treatment, the micro morphology of EG shows highly porous and irregular honeycomb network of piled graphene sheets (Figure 1b). The high specific surface area (30$\left.40 \mathrm{~m}^{2} / \mathrm{g}\right)$, low density $\left(2 \times 10^{-3}-10 \times 10^{-3} \mathrm{~g} / \mathrm{cm}^{3}\right)$ and a relatively high conductivity $(3-300 \mathrm{~S} / \mathrm{cm})$ make EG a promising carbon material ${ }^{51}$ and widely used in adsorption ${ }^{52}$, fire retardant ${ }^{53}$, electromagnetic interference shielding ${ }^{54}$, etc. 

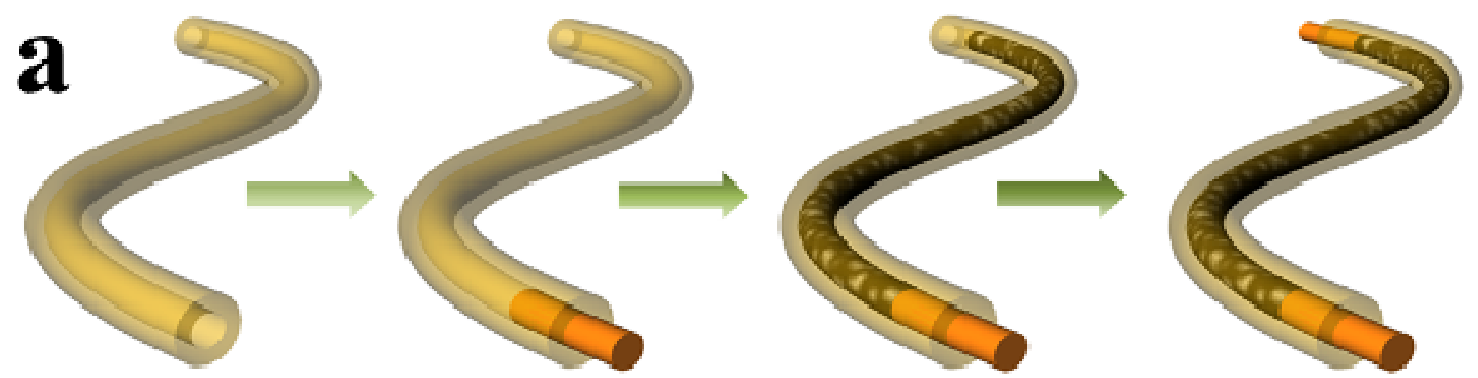

Latex rubber tubing

Half-sealed tubing

Filled tubing

Iubing conductor
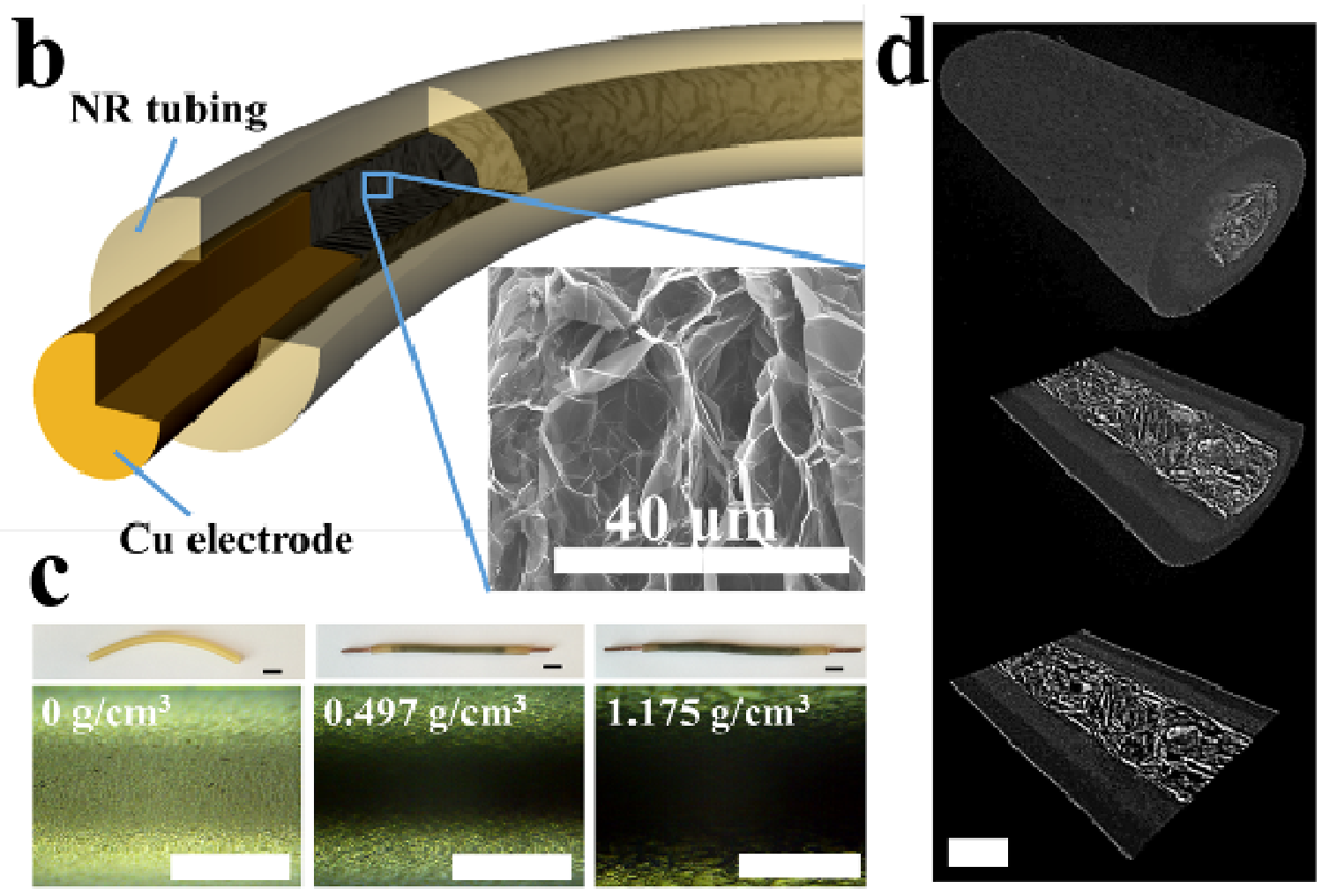

Figure 1 The structure schematic of the tubular conductor (TC): (a) the fabrication process of TC, (b) structure schematic of the TC (Inset: SEM image of the EG sheets used for packing), (c) photographs of TCs with various filling densities (left to right: $0 \mathrm{~g} / \mathrm{cm}^{3}, 0.497 \mathrm{~g} / \mathrm{cm}^{3}$ and $1.175 \mathrm{~g} / \mathrm{cm}^{3}$, scale bar: $0.5 \mathrm{~mm}$ ) (top) and optical micrographs of each sample under $300 \%$ strain (scale bar: $1 \mathrm{~mm}$ ) (bottom), and (d) reconstructed 3D tomography of TC $\left(1.175 \mathrm{~g} / \mathrm{cm}^{3}\right)$ with no cut, half-cut and single slice (scale bar: $500 \mu \mathrm{m}$ ).

EG was packed into an elastic natural rubber tubing to prepare compressible and macroconfined conductive components, as shown in Figure 1a, and observed by optical 
microscopy (Figure S1). In order to control the filling density of TCs, all the samples were fixed on a frame and marked before packing to make sure the same nominal packing length. The diameter $(d)$ and length $(l)$ of confined EG columns were measured for the calculation of packing (filling) density $\left(\rho_{d}\right)$ according the formula below:

$$
\rho_{d}=\frac{4 M}{\pi l d^{2}} \times 100 \%
$$

where $M$ denotes the packing mass of EG. The average value of 50 measurements was regarded as the packing density. It was noted that the rubber tubing swelled obviously as EG particles getting more compact. It can be seen from Figure 1c and Figure S1 that both the packing length and diameter of the TC with a filling density of $1.175 \mathrm{~g} / \mathrm{cm}^{3}$ are larger than those of TC $\left(0.497 \mathrm{~g} / \mathrm{cm}^{3}\right)$. Micro-CT scanning was applied to further investigate the 3D microscopic morphology of TCs. Figure 1d shows the 3D structure of the TC $\left(1.175 \mathrm{~g} / \mathrm{cm}^{3}\right)$, which was reconstructed from a stack of 1000 single 2D slices. Being confined in the rubber tubing, the percolation network of EG is believed with robust and reversible piezoresistivity when suffering loading and unloading because of the insignificant volume changing of rubber tubing under stretching ${ }^{55}$. 

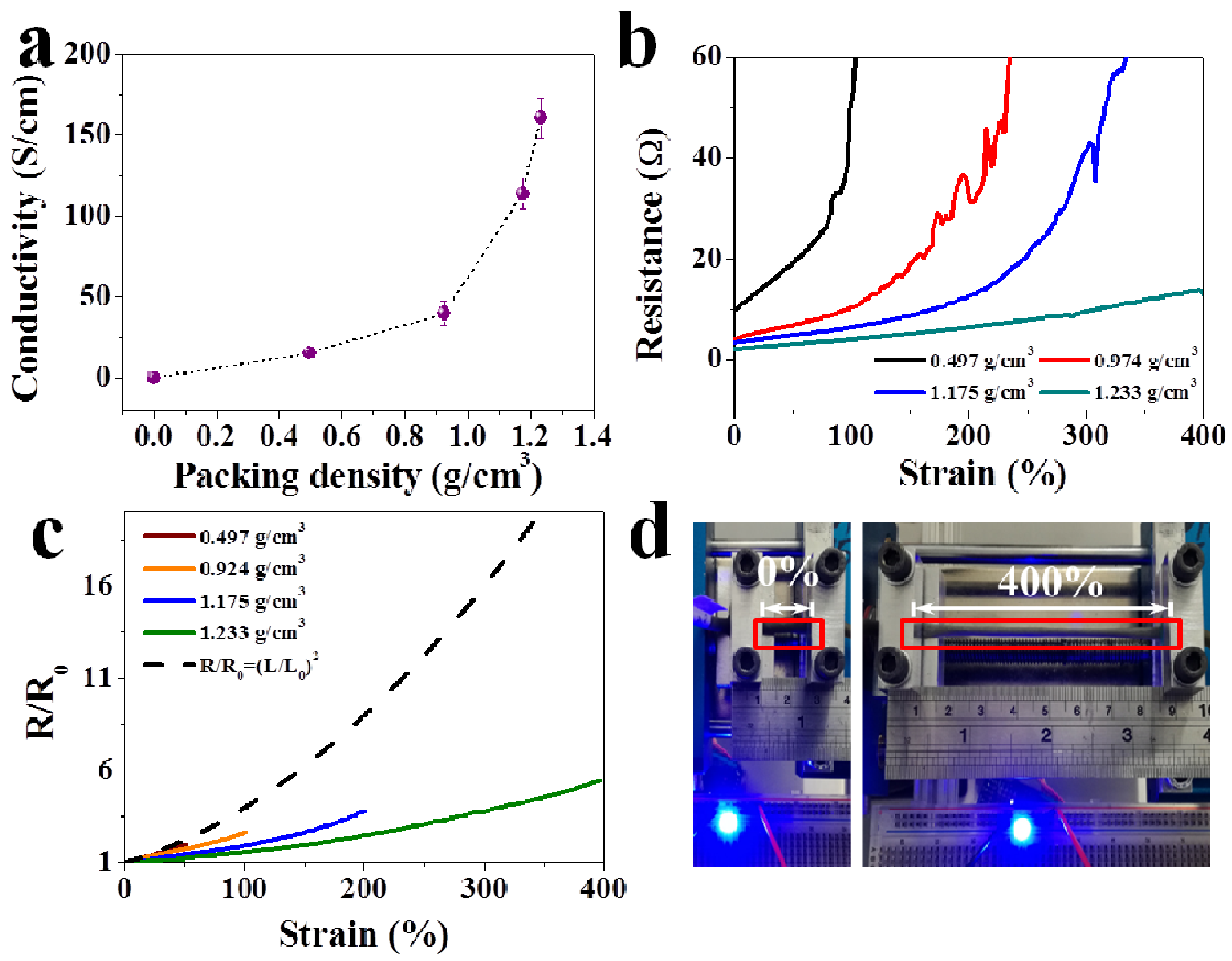

Figure 2 Basic electrical properties of stretchable TCs: (a) electrical conductivity of TCs with different filling densities, (b) resistance of TCs with different filling densities as a function of applied tensile strain, (c) relationship between normalized resistance $\left(R / R_{0}\right)$ and strain under effective working ranges, (d) photographs of a LED in the TC $\left(1.233 \mathrm{~g} / \mathrm{cm}^{3}\right)$ integrated circuit (3 V applied): original (left), and stretching up to 400\% strain (right).

As shown in Figure 2a, the conductivity of TCs increases from $15.1 \mathrm{~S} / \mathrm{cm}$ to $160.6 \mathrm{~S} / \mathrm{cm}$ with increasing filling density, which are significantly higher than the values of some stretchable conductors, e.g. 0.1-9.8 S/cm, reported in previous works ${ }^{6,8,20,46}$. Such a high conductivity is attributed to the direct contact of conductive EG particles without any interference from the insulated polymer matrix. Figure $\mathbf{2 b}$ displays the resistance of TCs with various filling densities as a function of tensile strain at a stretching speed of $60 \mathrm{~mm} / \mathrm{min}$. All 
samples show low resistances below $20 \Omega$ at initial stress-free state $\left(R_{0}\right)$. Even for TC with the lowest filling density of $0.497 \mathrm{~g} / \mathrm{cm}^{3}$, the resistance at $100 \%$ strain is also below $60 \Omega$. It is noted, though, the conducting channel becomes unstable for all TCs when the tensile strain is further increased. This brings the concept of effective stretchability (or working range) that means reversible and reliable responses of a sample under the strain range. ${ }^{56}$ So, the values for effective stretchability are determined as $50 \%, 100 \%, 200 \%$ and $400 \%$ for the 0.497 $\mathrm{g} / \mathrm{cm}^{3}, 0.924 \mathrm{~g} / \mathrm{cm}^{3}, 1.175 \mathrm{~g} / \mathrm{cm}^{3}$ and $1.233 \mathrm{~g} / \mathrm{cm}^{3}$ samples, respectively. All the samples show relatively good stability in their working ranges during 1000-times cyclic tests (Figure S2).

Figure 2c shows the strain dependence of the normalized resistance $\left(R / R_{0}\right)$ of TCs. The dotted curve represents the theoretic normalized resistance calculated from equation (2) by assuming the total volume is conserved, ${ }^{32}$ which were obeyed by devices based on ionic conductor $^{49}$ and liquid metal ${ }^{57}$ :

$$
\frac{R}{R_{0}}=\frac{\rho L S_{0}}{\rho_{0} L_{0} S}=\left(\frac{L}{L_{0}}\right)^{2}
$$

where $L$ and $S$ are the corresponding length and cross-sectional area of packed EG column in the tubing, while the subscript 0 refers to the original un-stretched state. The normalized conductivity $\left(\sigma / \sigma_{0}\right)$ equals to 1 as deduced in equation (3) below:

$$
\frac{\sigma}{\sigma_{0}}=\frac{L R_{0} S_{0}}{R S L_{0}}=\frac{R_{0}}{R}\left(\frac{L}{L_{0}}\right)^{2}=1
$$

It can be observed that all the normalized resistance data of TCs stay below the theoretical curve. As a result, all the normalized conductivity data of TCs are greater than the theoretical dotted line displayed in Figure S3. This means the normalized conductivity of TCs increases with increasing tensile strain. This result can be attributed to the orientation and sliding of packed layer-structured EG nanoparticles along the stretching direction, which maintained 
the electron-conductive paths under large strains. The high conductivity and excellent effective stretchability make these TCs surpass both film-based stretchable conductors, which have a high conductivity but a low working range (generally $<100 \%)^{27,47,58,59}$, and the conductive polymer-based gels, which have a high effective stretchability but low conductivity $^{32}$. The keeping of excellent conductivity under stretching was demonstrated in Figure 2d by the well-functioned LED light with a similar light brightness even under $400 \%$ strain.

From the discussion above, it is clear that TCs with different packing densities show similar trends of $R / R_{0}$ with growing strain. As an example, the response of TC with a packing density of $1.175 \mathrm{~g} / \mathrm{cm}^{3}$ is illustrated in Figure 3a. The curve can be divided into three different stages. When being stretched below 50\% strain (stage 1), the wriggling and sliding of compacted EG particles are insignificant, so the increase of $R / R_{0}$ is quite slow. As further strain is applied below $250 \%$ strain (stage 2), more noticeable growing of $R / R_{0}$ can be observed. A distinct sharp increasing of $R / R_{0}$, finally, can be detected when the stretching strain is above $250 \%$ (stage 3 ). Such different stages of the changing $R / R_{0}$ are considered to be related to the evolution of the percolation network of EG particles.

Considering the previous researches of conductive elastomers ${ }^{47,60,61}$, the piezoresistivity of TC can be described by models based on tunneling effect, in which the total resistance $R$ is described using equation (4):

$$
R=\left(\frac{P}{N}\right)\left(\frac{8 \pi h s}{3 \gamma a^{2} e^{2}}\right) \exp (\gamma s)
$$

where $N$ is the number of conducting paths, $P$ is the number of particles forming a single conducting path, $a^{2}$ is the effective cross-section, $e$ is the electron charge, $h$ is the Plank constant, and $s$ is the smallest distance between conductive particles. Here, $\gamma$ is calculated using equation (5). 


$$
\gamma=\frac{4 \pi}{h} \sqrt{2 \varphi m}
$$

where $\varphi$ is the height of the potential barrier between adjacent particles and $m$ is the electron mass. Similar to the model reported by Chen et al. ${ }^{62}, R / R_{0}$ at stages $1-2$ and stage 3 can be expressed by equations (6) and (7).

$$
\begin{gathered}
\frac{R}{R_{0}}=(1+\varepsilon) \exp (A \varepsilon+B) \\
\frac{R}{R_{0}}=(1+\varepsilon) \exp \left(A \varepsilon^{2}+B \varepsilon\right)
\end{gathered}
$$

Here, $\varepsilon$ is the strain, $A$ and $B$ are the fitting constants. As can be seen in Figure 3a, there is a good agreement between the fitting curves and the experiment data, which suggests that the tunneling effect plays an important role in the transportation of charge carriers in TCs. The piezoresistivity of TCs under effective stretchabilities, as shown in Figure 3b, can also be well fitted by equation (6). The fitted results are further listed in Table S1.

In order to further understand the observed phenomenon during stretching, the possible mechanism of the piezoresistive behavior of the TCs is proposed. As can be seen in Figure 3c, the shortest distance between two EG particles $\left(D_{s}\right)<$ the size of EG particles $\left(D_{t}\right)$ at stage 1, where the joining type between particles is governed by total connection. At this stage, the growth of resistance is slow and only the increasing tunneling resistance contributes to the rise of resistance. With further stretching, most tunneling connection gradually becomes disconnected in stage 2 , causing a faster increase of resistance than that during stage 1 . The continuous stretching finally leads to partial damage of the topology of EG network when $D_{s}$ $>$ the cut-off distance $\left(D_{c}\right)^{31}$ and results in disconnection, evidenced by the drastically resistance growing (stage 3). 

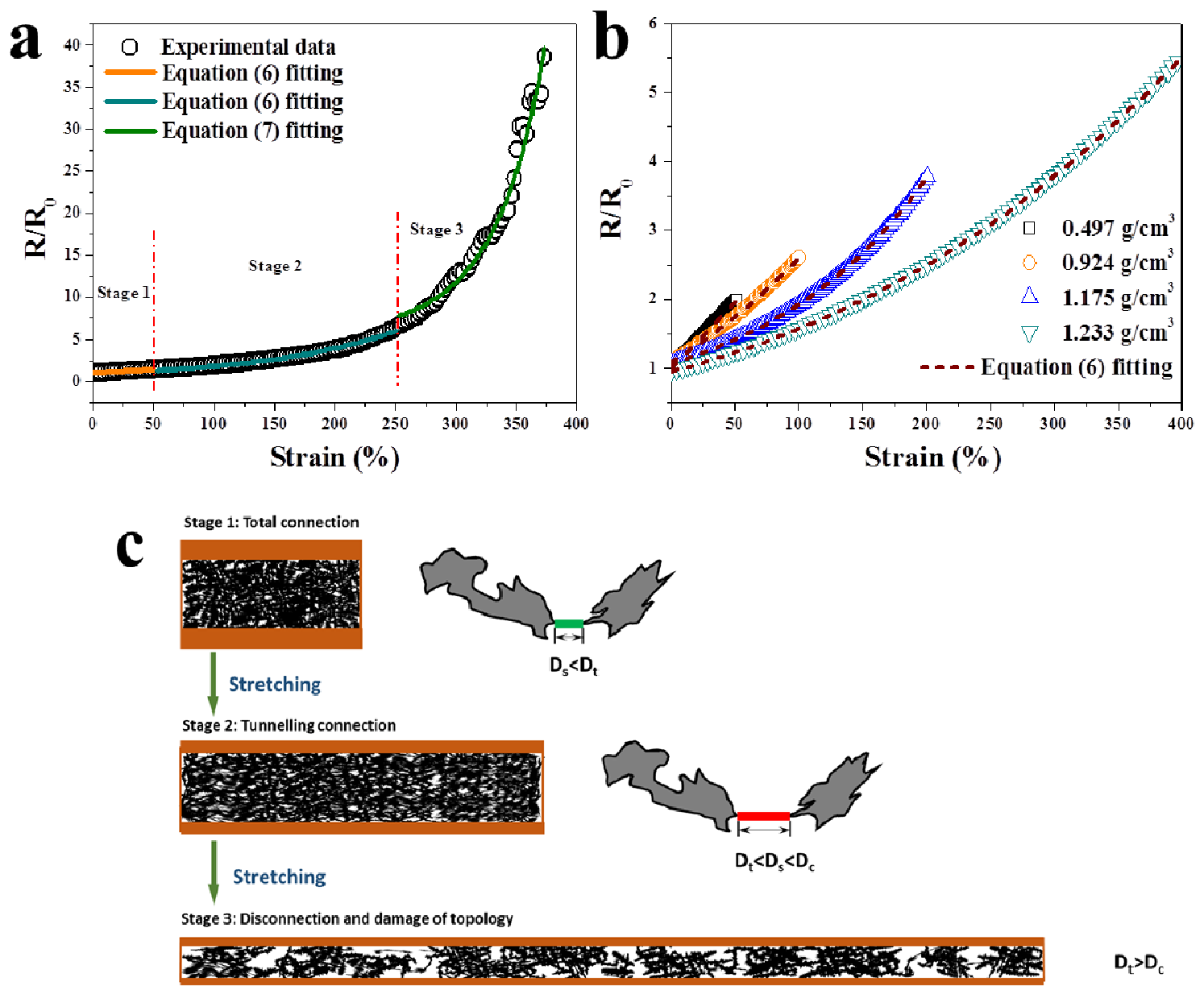

Figure 3 Quasi-static piezoresistive behavior of TCs. (a) Fitting $R / R_{0}$ curves of TC $(1.175$ $\mathrm{g} / \mathrm{cm}^{3}$ ) for three stretching stages. (b) Fitting curves of $R / R_{0}$ as a function of strain of TCs under corresponding stretchabilities. (c) Schematic illustration of EG conductive network packed in TC under three stretching stages.

To verify the above proposed mechanism, micro-CT scanning was applied to obtain the change of the percolation network of EG during stretching. Uniform inter-connected EG particles can be seen under stress-free state (Figure 4a). As stretching goes, EG particles suffer compression on the radial direction and orient towards the stretching direction, which results in sparser network and some local detachment (Figure 4b). When being stretched to $400 \%$ strain, particles are unconnected and the uniform topology of EG particles becomes inhomogeneous (Figure 4c). The area percent of EG extracted from CT slices is found 
decreasing with growing strain (Figure 4f). In Figure 4g, through comparing samples with various EG packing densities at $250 \%$ strain, TC $\left(1.175 \mathrm{~g} / \mathrm{cm}^{3}\right)$ maintains uniform and dense EG network with a high area percent over $90 \%$ sample, which guarantees the effective connection of the percolation network and stable electronic properties.
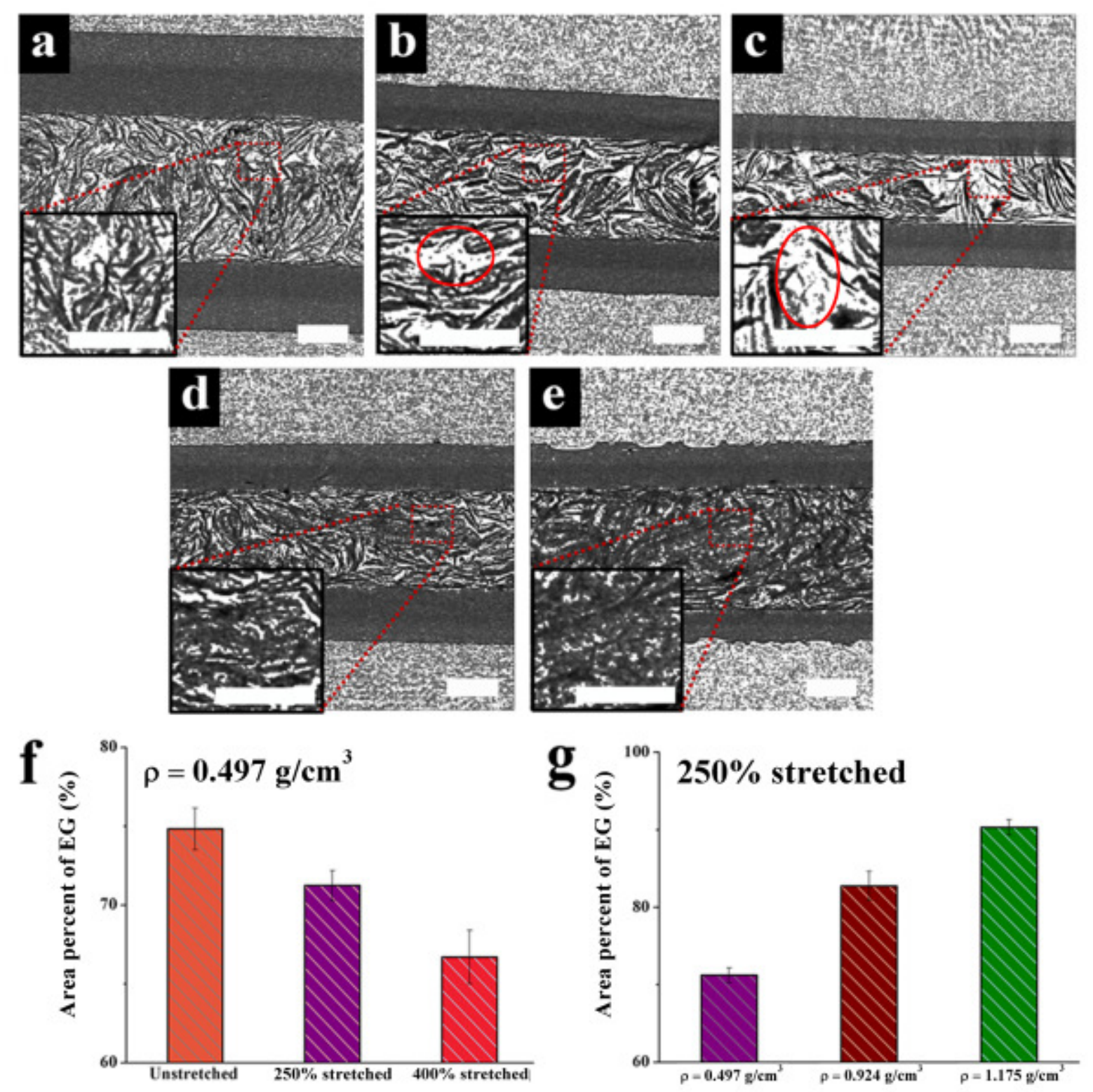

Figure 4 Morphology of TC with different stretching strains and packing densities: (a) $\rho=$ $0.497 \mathrm{~g} / \mathrm{cm}^{3}, 0 \%$ stretched. (b) $\rho=0.497 \mathrm{~g} / \mathrm{cm}^{3}, 250 \%$ stretched. (c) $\rho=0.497 \mathrm{~g} / \mathrm{cm}^{3}, 400 \%$ stretched. (d) $\rho=0.924 \mathrm{~g} / \mathrm{cm}^{3}, 250 \%$ stretched. (e) $\rho=1.175 \mathrm{~g} / \mathrm{cm}^{3}, 250 \%$ stretched (scale 
bar: $500 \mu \mathrm{m}$ ). The statistical results of the EG area percent in CT slices with different (f) stretching strains and $(\mathrm{g})$ packing densities.

In practice, the weak adhesion between the rigid conductive film and soft polymer substrate caused irreversible disconnection of conducting channels, which were adverse to the reliability of strain sensors, especially under large deformations ${ }^{63,64}$. The resistance response of TC $\left(0.924 \mathrm{~g} / \mathrm{cm}^{3}\right)$ with cyclic strains from $50 \%$ to $200 \%$ with a $50 \%$ increment is shown in Figure S4 It is noticed that the resistance of our TC can be fully recovered to the original value after the loading is released, through a hysteresis manner due to the resilient behavior of rubber tubing (Figure S5a). It is worth to mention that the response of our TCs is different from that of some film-based ${ }^{65}$ or blend ${ }^{66}$ strain sensors, for which the resistance cannot fully recover after releasing the loading. 

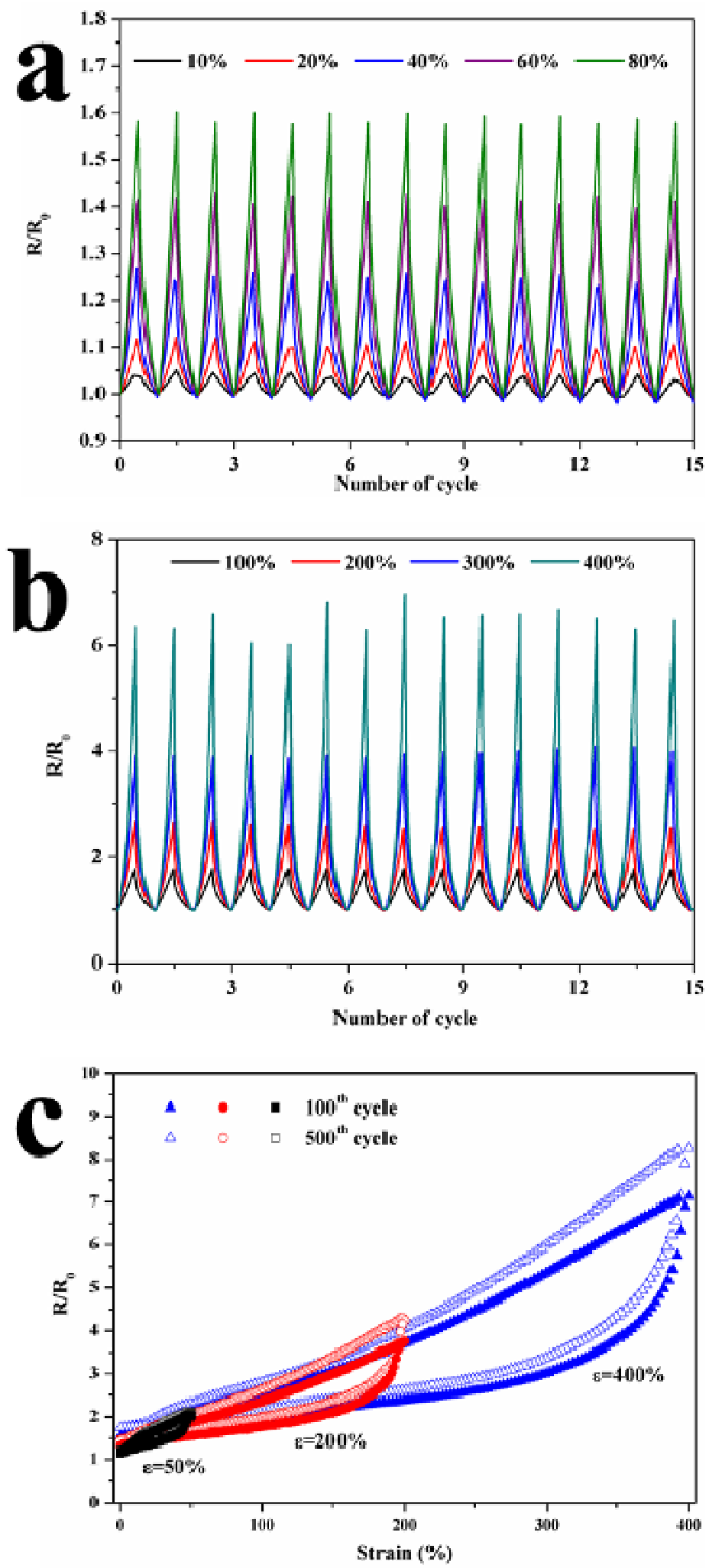

Figure $5 \mathrm{R} / \mathrm{R}_{0}$ of TC $\left(1.233 \mathrm{~g} / \mathrm{cm}^{3}\right)$ during 15 loading-unloading cycles under different strains (a) and (b). (c) $R / R_{0}$ versus strain of TC $\left(1.233 \mathrm{~g} / \mathrm{cm}^{3}\right)$ for the $100^{\text {th }}$ and $500^{\text {th }}$ cycle under 500 $\mathrm{mm} / \mathrm{min}$ testing speed. 
With the purpose of testifying the dynamic properties of TC, the normalized resistance responses over 15 cycles with a maximum applied strain from $10 \%$ to $400 \%$ were investigated. It is seen from Figure 5a and Figure $\mathbf{5 b}$ that distinctive and stable responses of $R / R_{0}$ are obtained. For TC with a lower packing density of $0.924 \mathrm{~g} / \mathrm{cm}^{3}$, as shown in Figure S6, a very small strain of $0.75 \%$ can still be distinguished. Due to the increasing friction and sliding of EG particles when TC was tested under a larger clamping distance, more obvious responses of resistance to stretching strain are observed. Cyclic tests with different speeds shown in Figure S7 suggest reliable resistance response can be maintained even under the maximum tensile strain of $400 \%$ and a maximum speed of $500 \mathrm{~mm} / \mathrm{min}$. Figure $\mathbf{5 c}$ presents the resistance responses of TC $\left(1.233 \mathrm{~g} / \mathrm{cm}^{3}\right)$ to strain for the $100^{\text {th }}$ and the $500^{\text {th }}$ cycle under $500 \mathrm{~mm} / \mathrm{min}$ speed, which shows relatively good stability. These cyclic tests suggest good reliability of our TCs for potential use as strain sensors (Movie S1). 

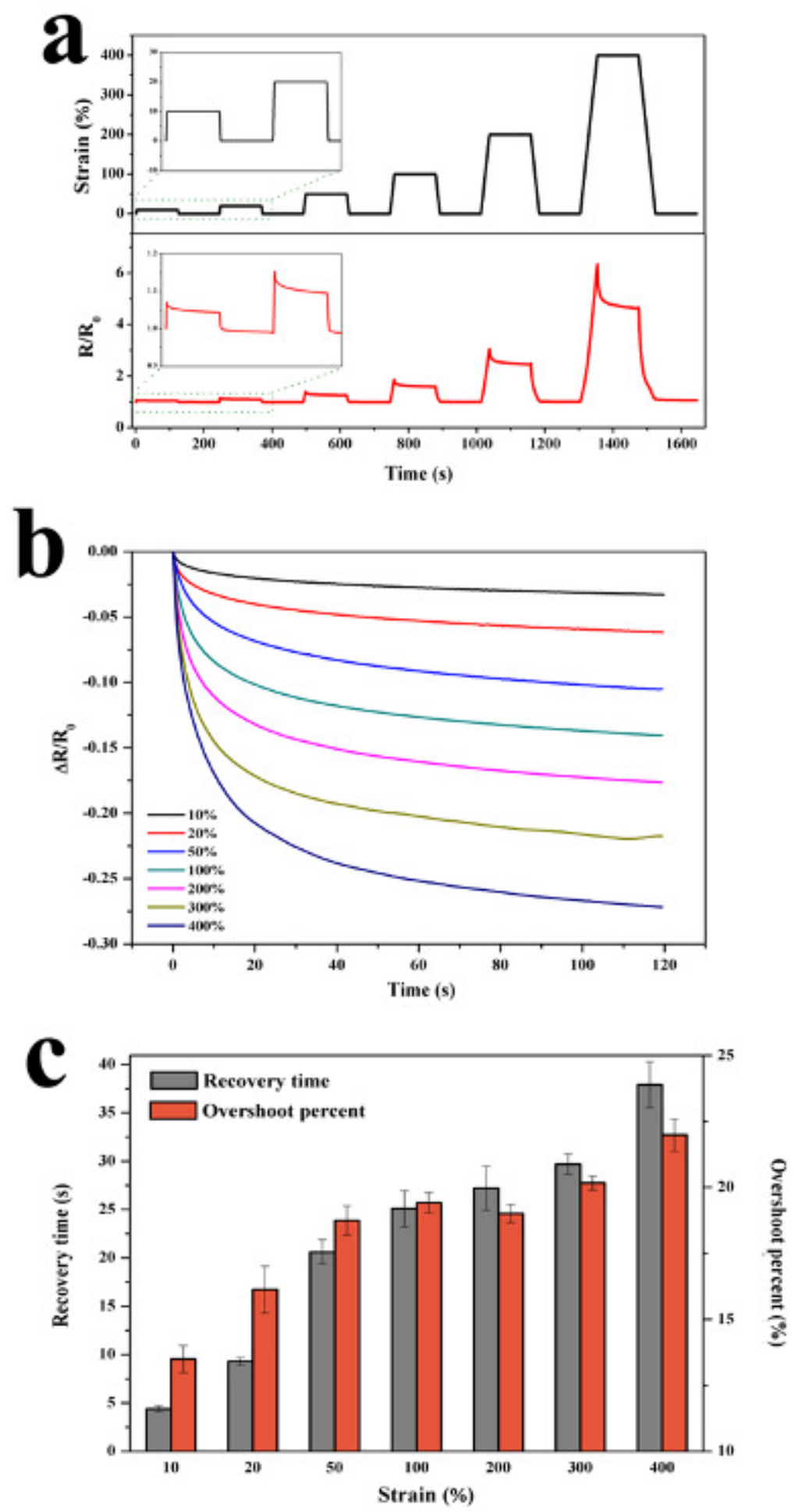

Figure 6 (a) Stretching-holding-releasing measurements of TC $\left(1.233 \mathrm{~g} / \mathrm{cm}^{3}\right)$ with a holding time of $120 \mathrm{~s}$ and a speed of $60 \mathrm{~mm} / \mathrm{min}$. (b) The relaxation curves of TC $\left(1.233 \mathrm{~g} / \mathrm{cm}^{3}\right)$ under various tensile strains. The original resistance at the beginning of holding region was noted as $R_{0}$. (c) Relaxation recovery time and overshoot percent of TC $\left(1.233 \mathrm{~g} / \mathrm{cm}^{3}\right)$ under various tensile strains. 
To further evaluate the dynamic response of TCs, the samples were subject to a stretchingholding-releasing measurement. In Figure 6a it can be seen that when the strain is held at the end of stretching, $R / R_{0}$ decreases slowly, which is known as overshoot ${ }^{56}$, caused by stress relaxation of the rubber tubing and sliding of the packed EG particles. In Figure $\mathbf{6 b}$, it is obvious that the relaxation-induced reduction of $R / R_{0}$ increases with tensile strain. In order to evaluate the relaxation behavior of TCs, the first derivative of $\Delta R / R_{0}$ versus time is calculated, and the relaxation recovery time is defined when the first derivatives reached 0.001 (Figure S8a). Meanwhile, the overshoot percent $(\eta)$ (Figure S8b) was also examined according to the formula below ${ }^{62}$ :

$$
\eta=\frac{R_{m}}{R_{s}} \times 100 \%
$$

where $R_{m}$ is the relaxation-induced reduction of resistance, and $R_{s}$ is the increment of resistance during the stretching stage. The results of relaxation recovery time and overshoot percent are shown in Figure 6c. Upon growing strain from $10 \%$ to $400 \%$, the relaxation recovery time increases from $4.4 \mathrm{~s}$ to $37.9 \mathrm{~s}$ and overshooting rises from $12.8 \%$ to $22.1 \%$, respectively. It should be noted that the overshoot and relaxation are commonly observed for resistive strain sensors ${ }^{67-68}$. Similar phenomenon has also been reported in the research of graphene/natural rubber composites. ${ }^{67}$

Stretchable conductors with high conductivity can be used as electrodes and interconnections, while stretchable conductors with good piezoresistivity have potential for serving as resistors and strain sensors ${ }^{69}$. It can be seen from the above discussion that TCs can generate distinctive feedback of resistance to a specific strain input. Although the gauge factor $\left(G F=\left(\Delta R / R_{0}\right) / \varepsilon\right)$ of TCs $(0.6-3)$ is in the same order of magnitude of conventional metal-foil-based strain gauges ${ }^{70}$ (Figure S9), the effective working range of the TCs reported herein is much higher than that of the metal-based stretchable electronics $(<5 \%){ }^{56}$ 
Compared to some stretchable conductors reported in the literature (listed in Table S2), our TCs show a good combination of high stretchability, conductivity and piezoresistivity, which are promising for not only high-performance interconnections, but also excellent strain sensors with a wide working range.
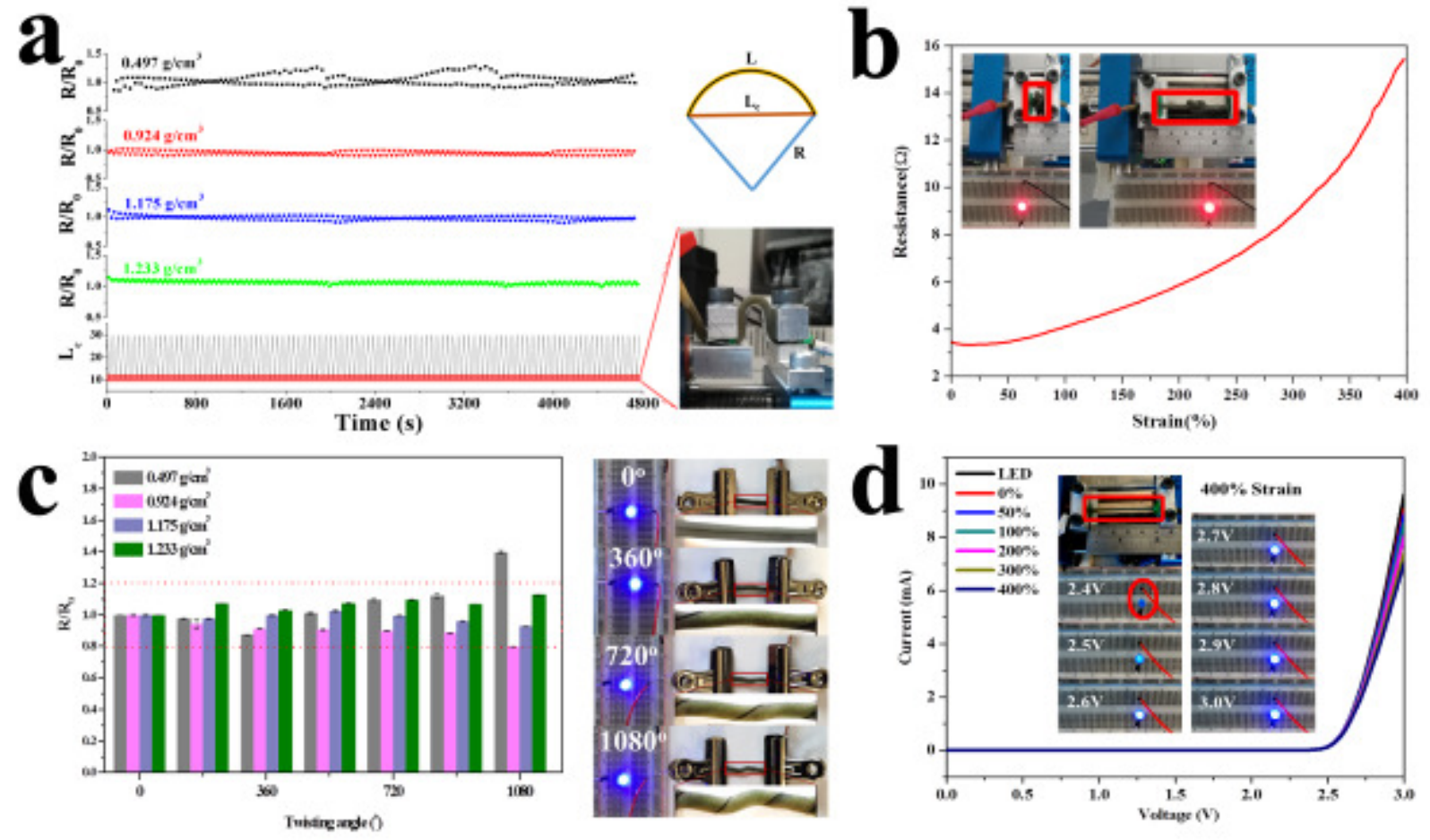

Figure 7 (a) $R / R_{0}$ of TCs during repeated bending tests. (b) Resistance change of a knotted TC $\left(1.233 \mathrm{~g} / \mathrm{cm}^{3}\right)$ during stretching from $0 \%$ to $400 \%$. (c) Relationship between $R / R_{0}$ and twisting angle of TCs, and photographs of a LED in the testing circuit with TC $\left(1.233 \mathrm{~g} / \mathrm{cm}^{3}\right)$ under different twisting states. (d) Current-Voltage measurements of the LED circuit without and with TC $\left(1.233 \mathrm{~g} / \mathrm{cm}^{3}\right)$ interconnected at various tensile strains. Insets of (d) show the brightness of LED integrated circuits interconnected with $400 \%$ stretched TC under different output voltages.

Figure 7a shows the resistance change of TCs against time over $100180^{\circ}$-bending cycles. While the resistance change is obvious for TCs with a low packing density, the fluctuation amplitude is still lower than 0.5. Meanwhile, this fluctuation becomes weaker with increasing 
packing density. A similar relationship between $R / R_{0}$ and the twisting angle is observed in Figure 7c. Excellent electrical stability of TCs is demonstrated by insignificant degradation of LED brightness during twisting and knotting-stretching operations as shown in Figure 7c (right) and the inset of Figure 7b. The I-V relationship of a LED integrated with TC (1.233 $\mathrm{g} / \mathrm{cm}^{3}$ ) in series was examined under various tensile strains (Movie S2). Although the current declined with increasing strain, all I-V curves in Figure 7d are close to the curve of single LED.
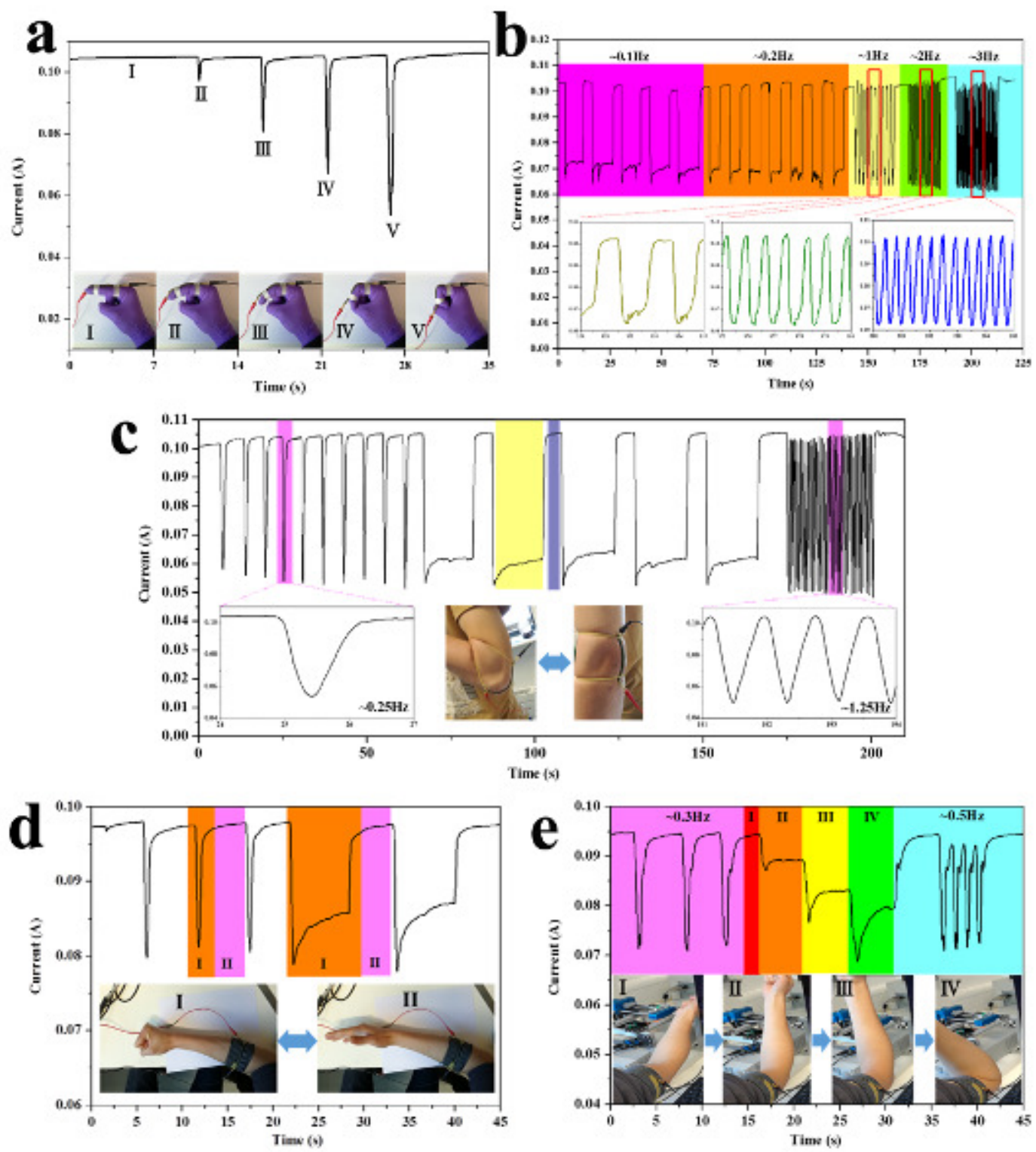

Figure 8 Response of current signal of a TC $\left(1.175 \mathrm{~g} / \mathrm{cm}^{3}\right)$ strain sensor to detect movements of human joints and muscles: (a) different bending-releasing motions of a finger, (b) finger 
motions with different frequencies, (c) arm joint bending-releasing motions with different frequencies, (d) the movement of muscles on forearm, and (e) the motions of muscles on upper arm with different frequencies.

As an example, TC with a packing density of $1.175 \mathrm{~g} / \mathrm{cm}^{3}$ was used to successfully detect and monitor the bending degree of fingers with different patterns (Figure 8a and Figure 8b), joint motions (Figure 8c), and the movements of muscles (Figure 8d and Figure 8e). More details can be found in Movie S3 and Movie S4. Besides, owing to the high conductivity of these TCs, the working voltage of the sensor can be several orders of magnitude lower than some reported strain sensors ${ }^{68-69}$. This means the device can run with lower energy cost. Thus, this work provides a new design of highly conductive, stretchable devices with strain sensing capability, which has potential in applications such as evaluation of athlete training systems, physical data collection of patients and other significant terminal equipment for smart life.

\section{CONCLUSIONS}

A novel method was proposed to fabricate low-cost, high-performance tubular stretchable conductors based on a confined structure of EG. The confined space inside the elastic tubing gave the packed EG particles a robust and stable percolation network so that tubular conductors were still characterized with excellent electrical conductivity under stretching. The tubular conductor with a packing density of $1.233 \mathrm{~g} / \mathrm{cm}^{3}$ obtained an outstanding conductivity of $160.6 \mathrm{~S} / \mathrm{cm}$ and good reliability with a maximum effective stretchability of $400 \%$. The piezoresistive behavior of tubular conductors was explained based on tunnel effect. The electrical conductivity, piezoresistive sensitivity and working strain of tubular 
conductors could be tuned by varying the content of EG, and excellent responsiveness and stability of tubular conductors under both low and high stretching speeds were achieved. These tubular conductors were also able to detect human motions including movement of fingers, arm joints and muscles for wearable electronics.

\section{ASSOCIATED CONTENT}

\section{Supporting Information}

Additional figures, tables and movies include: optical images of TC with different filling densities, results of 1000 cyclic stretching tests, relationship between normalized resistance $\left(R / R_{0}\right)$ and strain under effective stretching ranges, response of TC under cyclic strains from $50 \%$ to $200 \%$ with a $50 \%$ increment, cycling tensile curves of neat NR tubing and tensile stress-strain curves of TCs with different packing densities, $R / R_{0}$ response of TC under 50 stretching-releasing cycles with low stretching strains from $0.75 \%$ to $4 \%, 400 \%$ cyclic tests under various testing speeds, derivative of $\Delta R / R_{0}$ plotted with time and overshoot behavior of TC and tensile curves of natural rubber tubing and TC, gauge factor of TCs plotted with tensile strain, fitted A and B values and $\mathrm{R}^{2}$ values of TCs based on tunneling effect, summary of performance of stretchable conductors reported recently, movies of cyclic tests under 500 $\mathrm{mm} / \mathrm{s}$ testing speeds, I-V measurements, and detection of muscles movements (AVI).

\section{AUTHOR INFORMATION}

\section{Corresponding Author}

*E-mail: b.chen@qub.ac.uk, hwzou@163.com

\section{Funding Sources}


The authors would like to thank the Chinese Scholarship Council and European Commission's Horizon 2020 research and innovation program for funding this research (Grant Number: 656467 - SUPRONICS - H2020-MSCA-IF-2014).

\section{Notes}

The authors declare no competing financial interest.

\section{REFERENCES}

(1) Chortos, A.; Koleilat, G. I.; Pfattner, R.; Kong, D. S.; Lin, P.; Nur, R.; Lei, T.; Wang, H. L.; Liu, N.; Lai, Y. C.; Kim, M. G.; Chung, J. W.; Lee, S.; Bao, Z. N. Mechanically Durable and Highly Stretchable Transistors Employing Carbon Nanotube Semiconductor and Electrodes. Adv. Mater. 2016, 28, 4441-4448.

(2) Chae, S. H.; Yu, W. J.; Bae, J. J.; Duong, D. L.; Perello, D.; Jeong, H. Y.; Ta, Q. H.; Ly, T. $\mathrm{H}$; Vu, Q. A.; Yun, M.; Duan, X. F.; Lee, Y. H. Transferred Wrinkled $\mathrm{Al}_{2} \mathrm{O}_{3}$ for Highly Stretchable and Transparent Graphene-Carbon Nanotube Transistors. Nat. Mater. 2013, 12, 403-409.

(3) Xu, F.; Wu, M. Y.; Safron, N. S.; Roy, S. S.; Jacobberger, R. M.; Bindl, D. J.; Seo, J. H.; Chang, T. H.; Ma, Z. Q.; Arnold, M. S. Highly Stretchable Carbon Nanotube Transistors with Ion Gel Gate Dielectrics. Nano. Lett. 2014, 14, 682-686.

(4) Lee, S. K.; Kim, B. J.; Jang, H.; Yoon, S. C.; Lee, C.; Hong, B. H.; Rogers, J. A.; Cho, J. H.; Ahn, J. H. Stretchable Graphene Transistors with Printed Dielectrics and Gate Electrodes. Nano. Lett. 2011, 11, 4642-4646.

(5) Kim, R. H.; Bae, M. H.; Kim, D. G.; Cheng, H. Y.; Kim, B. H.; Kim, D. H.; Li, M.; Wu, J.; Du, F.; Kim, H. S.; Kim, S.; Estrada, D.; Hong, S. W.; Huang, Y. G.; Pop, E.; Rogers, J. A. Stretchable, Transparent Graphene Interconnects for Arrays of Microscale Inorganic Light Emitting Diodes on Rubber Substrates. Nano. Lett. 2011, 11, 3881-3886.

(6) Sekitani, T.; Nakajima, H.; Maeda, H.; Fukushima, T.; Aida, T.; Hata, K.; Someya, T. Stretchable Active-Matrix Organic Light-Emitting Diode Display Using Printable Elastic Conductors. Nat. Mater. 2009, 8, 494-499.

(7) Yin, D.; Feng, J.; Ma, R.; Liu, Y. F.; Zhang, Y. L.; Zhang, X. L.; Bi, Y. G.; Chen, Q. D.; Sun, H. B. Efficient and Mechanically Robust Stretchable Organic Light-Emitting Devices By a Laser-Programmable Buckling Process. Nat. Commun. 2016, 7, 11573.

(8) Fan, Q. Q.; Qin, Z. Y.; Gao, S. L.; Wu, Y. T.; Pionteck, J.; Mader, E.; Zhu, M. F. The Use of a Carbon Nanotube Layer on a Polyurethane Multifilament Substrate for Monitoring Strains as Large as 400\%. Carbon 2012, 50, 4085-4092. 
(9) Muth, J. T.; Vogt, D. M.; Truby, R. L.; Menguc, Y.; Kolesky, D. B.; Wood, R. J.; Lewis, J. A. Embedded 3D Printing of Strain Sensors within Highly Stretchable Elastomers. Adv. Mater. 2014, 26, 6307-6312.

(10) Suzuki, K.; Yataka, K.; Okumiya, Y.; Sakakibara, S.; Sako, K.; Mimura, H.; Inoue, Y. Rapid-Response, Widely Stretchable Sensor of Aligned MWCNT/Elastomer Composites for Human Motion Detection. ACS Sensors 2016, 1, 817-825.

(11) Ma, T.; Wang, Y.; Tang, R.; Yu, H. Y.; Jiang, H. Q. Pre-Patterned ZnO Nanoribbons on Soft Substrates for Stretchable Energy Harvesting Applications. J. Appl. Phys. 2013, 113, 524-528.

(12) Park, S.; Kim, H.; Vosgueritchian, M.; Cheon, S.; Kim, H.; Koo, J. H.; Kim, T. R.; Lee, S.; Schwartz, G.; Chang, H.; Bao, Z. A. Stretchable Energy-Harvesting Tactile Electronic Skin Capable of Differentiating Multiple Mechanical Stimuli Modes. Adv. Mater. 2014, $26,7324-7332$.

(13) Yi, F.; Lin, L.; Niu, S. M.; Yang, P. K.; Wang, Z. N.; Chen, J.; Zhou, Y. S.; Zi, Y. L.; Wang, J.; Liao, Q. L.; Zhang, Y.; Wang, Z. L. Stretchable-Rubber-Based Triboelectric Nanogenerator and Its Application as Self-Powered Body Motion Sensors. Adv. Funct. Mater. 2015, 25, 3688-3696.

(14) Jeong, C. K.; Lee, J.; Han, S.; Ryu, J.; Hwang, G. T.; Park, D. Y.; Park, J. H.; Lee, S. S.; Byun, M.; Ko, S. H.; Lee, K. J. A Hyper-Stretchable Elastic-Composite Energy Harvester. Adv. Mater. 2015, 27, 2866.

(15) Lamberti, A.; Clerici, F.; Fontana, M.; Scaltrito, L. A Highly Stretchable Supercapacitor Using Laser-Induced Graphene Electrodes onto Elastomeric Substrate. Adv. Energy Mater. 2016, 6, 50.

(16) Niu, Z. Q.; Dong, H. B.; Zhu, B. W.; Li, J. Z.; Hng, H. H.; Zhou, W. Y.; Chen, X. D.; Xie, S. S. Highly Stretchable, Integrated Supercapacitors Based on Single-Walled Carbon Nanotube Films with Continuous Reticulate Architecture. Adv. Mater. 2013, 25, 1058-1064.

(17) Tang, Q. Q.; Chen, M. M.; Wang, G. C.; Bao, H.; Saha, P. A Facile Prestrain-StickRelease Assembly of Stretchable Supercapacitors Based on Highly Stretchable and Sticky Hydrogel Electrolyte. J. Power Sources 2015, 284, 400-408.

(18) Wang, S. L.; Liu, N. S.; Su, J.; Li, L. Y.; Long, F.; Zou, Z. G.; Jiang, X. L.; Gao, Y. H. Highly Stretchable and Self-Healable Supercapacitor with Reduced Graphene Oxide Based Fiber Springs. ACS Nano 2017, 11, 2066-2074.

(19) Yu, X.; Su, X.; Yan, K.; Hu, H. W.; Peng, M.; Cai, X.; Zou, D. C. Stretchable, Conductive, and Stable PEDOT-Modified Textiles through a Novel In Situ Polymerization Process for Stretchable Supercapacitors. Adv. Mater. 2016, 1, 9.

(20) Keplinger, C.; Sun, J. Y.; Foo, C. C.; Rothemund, P.; Whitesides, G. M.; Suo, Z. G. Stretchable, Transparent, Ionic Conductors. Science 2013, 341, 984-987.

(21) Larson, C.; Peele, B.; Li, S.; Robinson, S.; Totaro, M.; Beccai, L.; Mazzolai, B.; Shepherd, R. Highly Stretchable Electroluminescent Skin for Optical Signaling and Tactile Sensing. Science 2016, 351, 1071-1074. 
(22) Choi, D. Y.; Kim, M. H.; Oh, Y. S.; Jung, S. H.; Jung, J. H.; Sung, H. J.; Lee, H. W.; Lee, H. M. Highly Stretchable, Hysteresis-Free Ionic Liquid -Based Strain Sensor for Precise Human Motion Monitoring. ACS Appl. Mater. Interfaces 2017, 9, 1770-1780.

(23) Bassil, M.; Davenas, J.; EL Tahchi, M. Electrochemical Properties and Actuation Mechanisms of Polyacrylamide Hydrogel for Artificial Muscle Application. Sens. Actuators B 2008, 134, 496-501.

(24) Kang, H.; Hwang, S.; Kwak, J. A Hydrogel Pen for Electrochemical Reaction and Its Applications for 3D Printing. Nanoscale 2015, 7, 994-1001.

(25) Cui, Z. X.; Zhou, M.; Greensmith, P. J.; Wang, W. K.; Hoyland, J. A.; Kinloch, I. A.; Freemont, T.; Saunders, B. R. A Study of Conductive Hydrogel Composites of pHResponsive Microgels and Carbon Nanotubes. Soft Matter 2016, 12, 4142-4153.

(26) Larmagnac, A.; Eggenberger, S.; Janossy, H.; Voros, J. Stretchable Electronics Based on Ag-PDMS Composites. Sci. Rep. 2014, 4, 7254.

(27) $\mathrm{Xu}, \mathrm{F}$; Zhu, Y. Highly Conductive and Stretchable Silver Nanowire Conductors. Adv. Mater. 2012, 24, 5117-5122.

(28) Gozen, B. A.; Tabatabai, A.; Ozdoganlar, O. B.; Majidi, C. High-Density Soft-Matter Electronics with Micron-Scale Line Width. Adv. Mater. 2014, 26, 5211-5216.

(29) Tang, S. Y.; Sivan, V.; Petersen, P.; Zhang, W.; Morrison, P. D.; Kalantar-zadeh, K.; Mitchell, A.; Khoshmanesh, K. Liquid Metal Actuator for Inducing Chaotic Advection. Adv. Funct. Mater. 2014, 24, 5851-5858.

(30) Shang, Y. Y.; He, X. D.; Li, Y. B.; Zhang, L. H.; Li, Z.; Ji, C. Y.; Shi, E. Z.; Li, P. X.; Zhu, K.; Peng, Q. Y.; Wang, C.; Zhang, X. J.; Wang, R. G.; Wei, J. Q.; Wang, K. L.; Zhu, H. W.; Wu, D. H.; Cao, A. Y. Super-Stretchable Spring-Like Carbon Nanotube Ropes. Adv. Mater. 2012, 24, 2896-2900.

(31) Oskouyi, A. B.; Sundararaj, U.; Mertiny, P. Tunneling Conductivity and Piezoresistivity of Composites Containing Randomly Dispersed Conductive Nano-Platelets. Materials 2014, 7, 2501-2521.

(32) Lee, Y. Y.; Kang, H. Y.; Gwon, S. H.; Choi, G. M.; Lim, S. M.; Sun, J. Y.; Joo, Y. C. A Strain-Insensitive Stretchable Electronic Conductor: PEDOT:PSS/Acrylamide Organogels. Adv. Mater. 2016, 28, 1636-1643.

(33) Wu, J.; Liow, C.; Tao, K.; Guo, Y. Y.; Wang, X. T.; Miao, J. M. Large-Area SubWavelength Optical Patterning via Long-Range Ordered Polymer Lens Array. ACS Appl. Mater. Interfaces 2016, 8, 16368-16378.

(34) Liu, H.; Gao, J. C.; Huang, W. J.; Dai, K.; Zheng, G. Q.; Liu, C. T.; Shen, C. Y.; Yan, X. R.; Guo, J.; Guo, Z. H. Electrically Conductive Strain Sensing Polyurethane Nanocomposites with Synergistic Carbon Nanotubes and Graphene Bifillers. Nanoscale 2016, 8, 12977-12989.

(35) Deng, H.; Ji, M. Z.; Yan, D. X.; Fu, S. R.; Duan, L. Y.; Zhang, M. W.; Fu, Q. Towards Tunable Resistivity-Strain Behavior Through Construction of Oriented and Selectively Distributed Conductive Networks in Conductive Polymer Composites. J. Mater. Chem. A 2014, 2, 10048-10058. 
(36) Zhan, Y. H.; Lavorgna, M.; Buonocore, G.; Xia, H. S. Enhancing Electrical Conductivity of Rubber Composites by Constructing Interconnected Network of Self-Assembled Graphene with Latex Mixing. J. Mater. Chem. 2012, 22, 10464-10468.

(37) Lin, Y.; Dong, X. C.; Liu, S. Q.; Chen, S.; Wei, Y.; Liu, L. Graphene-Elastomer Composites with Segregated Nanostructured Network for Liquid and Strain Sensing Application. ACS Appl. Mater. Interfaces 2016, 8, 24143-24151.

(38) Chen, Z. P.; Ren, W. C.; Gao, L. B.; Liu, B. L.; Pei, S. F.; Cheng, H. M. Threedimensional Flexible and Conductive Interconnected Graphene Networks Grown by Chemical Vapour Deposition. Nat. Mater. 2011, 10, 424-428.

(39) Li, X.; Zhang, R. J.; Yu, W. J.; Wang, K. L.; Wei, J. Q.; Wu, D. H.; Cao, A. Y.; Li, Z. H.; Cheng, Y.; Zheng, Q. S.; Ruoff, R. S.; Zhu, H. W. Stretchable and Highly Sensitive Graphene-on-Polymer Strain Sensors. Sci. Rep. 2012, 2, 870.

(40) Yu, Y.; Luo, S.; Sun, L.; Wu, Y.; Jiang, K. L.; Li, Q. Q.; Wang, J. P.; Fan, S. S. UltraStretchable Conductors Based on Buckled Super-Aligned Carbon Nanotube Films. Nanoscale 2015, 7, 10178-10185.

(41) Kaltenbrunner, M.; White, M. S.; Glowacki, E. D.; Sekitani, T.; Someya, T.; Sariciftci, N. S.; Bauer, S. Ultrathin and Lightweight Organic Solar Cells with High Flexibility. Nat. Commun. 2012, 3, 770.

(42) Son, D.; Lee, J.; Qiao, S.; Ghaffari, R.; Kim, J.; Lee, J. E.; Song, C.; Kim, S. J.; Lee, D. J.; Jun, S. W.; Yang, S.; Park, M.; Shin, J.; Do, K.; Lee, M.; Kang, K.; Hwang, C. S.; Lu, N. S.; Hyeon, T.; Kim, D. H. Multifunctional Wearable Devices for Diagnosis and Therapy of Movement Disorders. Nat. Nanotechnol. 2014, 9, 397-404.

(43) Jung, S. W.; Choi, J. S.; Koo, J. B.; Park, C. W.; Na, B. S.; Oh, J. Y.; Lee, S. S.; Chu, H. Y. Stretchable Organic Thin-Film Transistors Fabricated on Elastomer Substrates Using Polyimide Stiff-Island Structures. ECS Solid State Lett. 2015, 4, P1-P3.

(44) Kang, N.; Choi, W.; Kim, H.; Kim, C. S.; Jo, S. Transfer Printed Microcell Array for Stretchable Organic Solar Cells. ECS Solid State Lett. 2015, 4, P88-P90.

(45) Someya, T.; Kato, Y.; Sekitani, T.; Iba, S.; Noguchi, Y.; Murase, Y.; Kawaguchi, H.; Sakurai, T. Conformable, Flexible, Large-area Networks of Pressure and Thermal Sensors with Organic Transistor Active Matrixes. Proc. Natl. Acad. Sci. U.S.A. 2005, $102,12321-12325$.

(46) Zhang, Y. Y.; Sheehan, C. J.; Zhai, J. Y.; Zou, G. F.; Luo, H. M.; Xiong, J.; Zhu, Y. T.; Jia, Q. X. Polymer-Embedded Carbon Nanotube Ribbons for Stretchable Conductors. Adv. Mater. 2010, 22, 3027-3031.

(47) Amjadi, M.; Pichitpajongkit, A.; Lee, S.; Ryu, S.; Park, I. Highly Stretchable and Sensitive Strain Sensor Based on Silver Nanowire-Elastomer Nanocomposite. ACS Nano 2014, 8, 5154-5163.

(48) Park, J.; Wang, S. D.; Li, M.; Ahn, C.; Hyun, J. K.; Kim, D. S.; Kim, D. K.; Rogers, J. A.; Huang, Y. G.; Jeon, S. Three-dimensional Nanonetworks for Giant Stretchability in Dielectrics and Conductors. Nat. Commun. 2012, 3, 916. 
(49) Choi, D. Y.; Kim, M. H.; Oh, Y. S.; Jung, S. H.; Jung, J. H.; Sung, H. J.; Lee, H. W.; Lee, H. M. Highly Stretchable, Hysteresis-Free Ionic Liquid -Based Strain Sensor for Precise Human Motion Monitoring. ACS Appl. Mater. Interfaces 2017, 9, 1770-1780.

(50) Fassler, A. L. Application of Liquid-Metal GaIn Alloys to Soft-matter Capacitance and Related Stretchable Electronics. Carnegie Mellon University, 2016.

(51) Celzard, A.; Schneider, S.; Mareche, J. F. Densification of Expanded Graphite. Carbon 2002, 40, 2185-2191.

(52) Mondal, T.; Bhowmick, A. K.; Krishnamoorti, R. Synthesis and Characterization of BiFunctionalized Graphene and Expanded Graphite Using n-butyl Lithium and Their Use for Efficient Water Soluble Dye Adsorption. J. Mater. Chem. A 2013, 1, 8144-8153.

(53) Luo, W.; Li, Y.; Zou, H. W.; Liang, M. Study of Different-Sized Sulfur-Free Expandable Graphite on Morphology and Properties of Water-Blown Semi-Rigid Polyurethane Foams. RSC Adv. 2014, 4, 37302-37310.

(54) Chung, D. D. L. Materials for Electromagnetic Interference Shielding. J. Mater. Eng. Perform. 2000, 9, 350-354.

(55) Chenal, J. M.; Gauthier, C.; Chazeau, L.; Guy, L.; Bomal, Y. Parameters Governing Strain Induced Crystallization in Filled Natural Rubber. Polymer 2007, 48, 6893-6901.

(56) Amjadi, M.; Kyung, K. U.; Park, I.; Sitti, M. Stretchable, Skin-Mountable, and Wearable Strain Sensors and Their Potential Applications: A Review. Adv. Funct. Mater. 2016, 26, $1678-1698$.

(57) Zhu, S.; So, J. H.; Mays, R.; Desai, S.; Barnes, W. R.; Pourdeyhimi, B.; Dickey, M. D. Ultrastretchable Fibers with Metallic Conductivity Using a Liquid Metal Alloy Core. Adv. Funct. Mater. 2013, 23, 2308-2314.

(58) Ho, X. N.; Tey, J. N.; Liu, W. J.; Cheng, C. K.; Wei, J. Biaxially Stretchable Silver Nanowire Transparent Conductors. J. Appl. Phys. 2013, 113, 044311.

(59) Tian, H.; Shu, Y.; Cui, Y. L.; Mi, W. T.; Yang, Y.; Xie, D.; Ren, T. L. Scalable Fabrication of High-Performance and Flexible Graphene Strain Sensors. Nanoscale 2014, 6, 699-705.

(60) Zhang, X. W.; Pan, Y.; Zheng, Q.; Yi, X. S. Time Dependence of Piezoresistance for the Conductor-Filled Polymer Composites. J. Polym. Sci. Part B: Polym. Phys 2000, 38, 2739-2749.

(61) Wu, S.; Zhang, J.; Ladani, R. B.; Ravindran, A. R.; Mouritz, A. P.; Kinloch, A. J.; Wang, C. H. Novel Electrically Conductive Porous PDMS/Carbon Nanofiber Composites for Deformable Strain Sensors and Conductors. ACS Appl. Mater. Interfaces 2017, 9, 14207-14215.

(62) Chen L.; Chen G.; Lu L. Piezoresistive Behavior Study on FingerSensing Silicone Rubber/Graphite Nanosheet Nanocomposites. Adv. Funct. Mater. 2010, 17, 638-670.

(63) Lipomi, D. J.; Vosgueritchian, M.; Tee, B. C. K.; Hellstrom, S. L.; Lee, J. A.; Fox, C. H.; Bao, Z. N. Skin-Like Pressure and Strain Sensors Based on Transparent Elastic Films of Carbon Nanotubes. Nat. Nanotechnol. 2011, 6, 788-792. 
(64) Won, S.; Hwangbo, Y.; Lee, S. K.; Kim, K. S.; Kim, K. S.; Lee, S. M.; Lee, H. J.; Ahn, J. H.; Kim, J. H.; Lee, S. B. Double-Layer CVD Graphene as Stretchable Transparent Electrodes. Nanoscale 2014, 6, 6057-6064.

(65) Yamada, T.; Hayamizu, Y.; Yamamoto, Y.; Yomogida, Y.; Izadi-Najafabadi, A.; Futaba, D. N.; Hata, K. A Stretchable Carbon Nanotube Strain Sensor for Human-Motion Detection. Nat. Nanotechnol. 2011, 6, 296-301.

(66) Wang, D.; Li, H. Y.; Li, M. F.; Jiang, H. Q.; Xia, M.; Zhou, Z. Stretchable Conductive Polyurethane Elastomer in Situ Polymerized with Multi-Walled Carbon Nanotubes. $J$. Mater. Chem. C 2013, 1, 2744-2749.

(67) Boland, C. S.; Khan, U.; Backes, C.; O'Neill, A.; McCauley, J.; Duane, S.; Shanker, R.; Liu, Y.; Jurewicz, I.; Dalton, A. B.; Coleman, J. N. Sensitive, High-Strain, High-Rate Bodily Motion Sensors Based on Graphene-Rubber Composites. ACS Nano 2014, 8, 8819-8830.

(68) Mattmann, C.; Clemens, F.; Troster, G. Sensor for Measuring Strain in Textile. Sensors 2008, 8, 3719-3732.

(69) Trung, T. Q.; Lee, N. E. Recent Progress on Stretchable Electronic Devices with Intrinsically Stretchable Components. Adv. Mater. 2017, 29, 1603167.

(70) Zhao, J.; Zhang, G. Y.; Shi, D. X. Review of Graphene-Based Strain Sensors. Chi. Phys. B 2013, 22, 057701. 